\title{
PENFIGÓIDE CICATRICIAL: MANIFESTAÇÕES BUCAIS E TRATAMENTO COM CORTICOSTERÓIDES
}

Rafaeli SOUZA, Daniela CASTANHA, Karine FÁTIMA LYKO, Cassius TORRES PEREIRA

O penfigóide cicatricial é uma doença auto-imune de caráter crônico com característica clínica vesiculobolhosa. Lesões em mucosa bucal são observadas na maioria dos pacientes, no entanto mucosas conjuntiva, nasal, esofágica, laríngea e vaginal podem estar envolvidas. O objetivo desse trabalho é relatar a conduta clínica de um caso de penfigóide cicatricial. Paciente de 76 anos de idade, sexo masculino, leucoderma, compareceu à Clínica de Estomatologia da UFPR com queixa de inflamação gengival. Através de exame clínico constatou-se o quadro de gengivite descamativa, com manchas brancas em área de gengiva marginal, sem sintomatologia dolorosa. Para confirmação de diagnóstico realizou-se biópsia incisional na região, sendo o laudo do exame anatomopatológico inconclusivo, optou-se por prescrever bochecho com decadron elixir para reduzir a inflamação. Após a redução do quadro inflamatório realizou-se nova biópsia sendo o resultado penfigóide cicatricial. Para o uso de propionato de clobetasol $0,05 \%$ confeccionou-se uma placa de acetato, na qual o paciente inseriu o corticosteróide três vezes ao dia durante 20 minutos. Após terapêutica medicamentosa, houve remissão das lesões, sendo a medicação constante por 2 anos e meio. $O$ diagnóstico para penfigóide cicatricial deve ser estabelecido com o exame histopatológico e a terapêutica medicamentosa pode ser fundamental para o tratamento como foi no caso relatado.

Palavras-chave: Penfigóide Cicatricial; Mucosa Bucal; Corticosteroide 